\title{
Fracture Resistance of Endodontically Treated Mandibular Premolars Obturated with Different Sealers an In-Vitro Study
}

\author{
Salma Abdo ${ }^{1,2 *}$ \\ ${ }^{1}$ Dental Department, Mediclinic Hospitals Middle East, Abu Dhabi, UAE \\ ${ }^{2}$ Department of Dentistry, AlFarabi University College, Baghdad, Iraq \\ *Corresponding Author: Salma Abdo, Dental Department, Mediclinic Hospitals \\ Middle East, Abu Dhabi, UAE and AlFarabi University College, Baghdad, Iraq.
}

Received: January 23, 2021

Published: February 10, 2021

(C) All rights are reserved by Salma Abdo.

\begin{abstract}
Purpose: This study was design to compare the in vitro effects of different root canal sealers on the fracture resistance of endodontically treated teeth.

Materials and Methods: One hundred and fifty extracted human mandibular single rooted premolars were selected. A total of 125 out of the selected teeth were prepared usig twisted adaptive file. Twenty five samples had no treatment and were used as a positive control group (Group +ve). The 125 test teeth were further divided into 5 groups of 25 samples each. One of the 5 groups was designated as negative control (Group -ve) where teeth were prepared and left without obturation. Remaining groups were filled with totalfill point-TotalFill BC (Group 1), gutta-percha-AH plus (Group 2), gutta-percha- Apexit (Group 3), gutta perch- Tubliseal (Group 4). Fracture resistance of all samples was measured using the Instron testing machine.

Results: The results showed that the highest fracture resistance was observed in positive control group (Group +ve), followed by Groups 1, 2, 3, and 4 with values (in N) of 1279.3 (205.4), 958.1 (79.2), 888 (76.7), 736.1(66.5), 719.8 (56.8), respectively. The lowest fracture resistance force was seen in (Group -ve), which was measured at 493.5 (103.5). Statistical analysis for root fracture resistance showed highly significant difference between all groups with p value $<001$.

Conclusions: Based on this in vitro study, TotalFill bioceramic based sealer with totalfill points enhanced the fracture resistance of endodontically treated teeth when compared with other sealers.
\end{abstract}

Keywords: Fracture Resistance; Bioceramic; AHplus; Apexit; Tubliseal

\section{Introduction}

The main reason of the reduction of fracture resistance of endoddontically treated teeth is the massive loss of coronal tooth structure [1], which was caused by caries, fractures, and access preparations [2].

Endodontically treated teeth need to be obturated in a manner that would reinforce the remaining root canal system and provide a tight seal. This certainly depends on the properties of the sealer and filling materials [3]. Various root canal sealers have developed in the market to facilitate adhesion to root canal system, as adhesion and mechanical interlocking may reinforce the remaining root structure and reduce root fracture [3]. Zinc oxide-eugenol (ZOE) sealer (Kerr sealer-Rickert, California, USA) has been used successfully over an extended period of time, because it has antimicrobial activity, however, shrinkage on setting, solubility, and discoloration of the tooth structure are its main drawback $[4,5]$.

Calcium hydroxide $\mathrm{Ca}(\mathrm{OH})_{2}$ sealers Apexit Plus (Ivoclar Vivadent, Schaan, Liechtenstein) have a good antimicrobial activity. It 
could form a calcific barrier at the apical foramen by the release of calcium hydroxide. However this process eliminate its efficacy as a sealer $[6,7]$.

Epoxy resin-based sealer AH Plus (Dentsply, Konstanz, Germany) is characterized by very good mechanical properties, high radioopacity, low polymerization shrinkage and solubility. Resin-based root canal sealers have the ability to provide a tight seal between the root canal filling material and intraradicular dentin by penetrating into dentinal tubule $[8,9]$.

A new group of root canal sealers based on mineral trioxide aggregate (Bioceramic) (MTA) (Totalfill BC sealer) have been recently developed. These sealers are based on tricalcium silicate, a hydrophilic sealer. They are bioactivity, biocompatibility, antibacterial, and have excellent physico-chemical properties [10,11]. They have the ability to expand slightly rather than shrink during setting and create a tight seal between the dentin and filling material. Totalfill $\mathrm{BC}$ sealer releases free calcium ions $\left(\mathrm{Ca}_{2}+\right)$ and stimulate tissue regeneration which enhance healing process [12].

TotalFill BC Points are coated with bioceramic nanoparticles. This combination between the TotalFill BC Sealer and TotalFill BC Points create a strong bond and adhesion, which eliminate any gaps may present between a cement and a standard Gutta Percha point.

Therefore, the aim of this in vitro study was to investigate the fracture resistance root canals obturated with different types of sealers.

\section{Materials and Methods}

Selection of teeth

150 single-rooted mandibular premolar teeth were extracted for orthodontic purpose from patient age ranged from 15 to 25 years. These extracted teeth were examined under digital stereomicroscope (Motic Digital Microscope, Micro-Optic Industrial Group Co. LTD, France) to rule out any pre-existing root fractures. The premolars sectioned at the cementoenamel junction using a diamond disc at a high-speed handpiece under continuous water spray coolant, to remove the crown. All the root samples had the same curvature between $0^{\circ}-5^{\circ}$ (using Schneider technique) with apical foramen equals to K-file size 15/.02.Then the samples were randomly divided into 6 groups of 25 roots and kept in separate plastic container.

\section{Sample preparation}

Working length of all root canals was established using a size 15 K Flex file (Dentsply Tulsa Dental Specialties, Tulsa, OK, USA). File was placed and advanced into the root canal until its tip was visualized at the apical foramen. The working length was set at $1 \mathrm{~mm}$ shorter of the apical foramen. In Group 6 positive control group $n$ $=25$, the root canals were cleaned from pulpal residuals and sealed the orifice with temporary filling (cavit). While the other five root canal groups were instrumented with Twisted File Adaptive (TFA; SybronEndo, Orange, CA, USA) up to a size 35 taper 0.04 master apical file following manufacturer's instructions. During preparation and between each TFA file, the canals were irrigated with 1 $\mathrm{mL}$ of $5.25 \%$ Sodium hypochlorite (NaOCL). After instrumentation, the canals were rinsed initially with $5 \mathrm{~mL}$ of $17 \%$ ethylenediaminetetraacetic acid (EDTA) to remove the smear layer and followed by $2 \mathrm{~mL}$ of saline. The canals were dried using paper points. Then the root canal samples were randomly divided into five experimental groups of 25 roots each. Group 5 negative control was prepared and the orifice of the canal was closed with cavit. While the other four groups were divided according to the root canal sealer used and obturated with 35/.04 Gutta-percha points using lateral compaction technique.

- Group 1: Totalfill BC root canal sealer (FKG Dentaire, La Chaux-de-Fonds, Switzerland) and Totalfill points (FKG Dentaire, La Chaux-de-Fonds, Switzerland).

- Group 2: AH Plus (Dentsply, Konstanz, Germany) root canal sealer and Gutta-percha points

- Group 3: Apexit Plus (Ivoclar Vivadent, Schaan, Liechtenstein) root canal sealer and Gutta-percha points.

- Group 4: Tubli-Seal (Kerr Italia S.p.A., Salerno, Italy) root canal sealer and Gutta-percha points.

- Group 5: (negative Control); prepared roots unobturated.

- Group 6: (positive control): cleaned roots unprepared and unobturated.

All the roots were mounted in self-cured acrylic resin (Sofa Dental, Kerr Company, Germany) blocks exposing $4 \mathrm{~mm}$ of the coronal portion (Figure 1). The acrylic blocks were placed on the lower plate of the universal testing machine (Instron 5982, UK). The upper plate was fitted with $3 \mathrm{~mm}$ diameter steel spherical. The steel spherical tip was lowered to engage the entire coronal surface of the roots and subjected to a gradually increasing force $(1 \mathrm{~mm} /$ 
min), and directed parallel to the long axis of the roots (Figure 2). The force level at which the fracture occurred was measured and recorded in Newton (Figure 3).

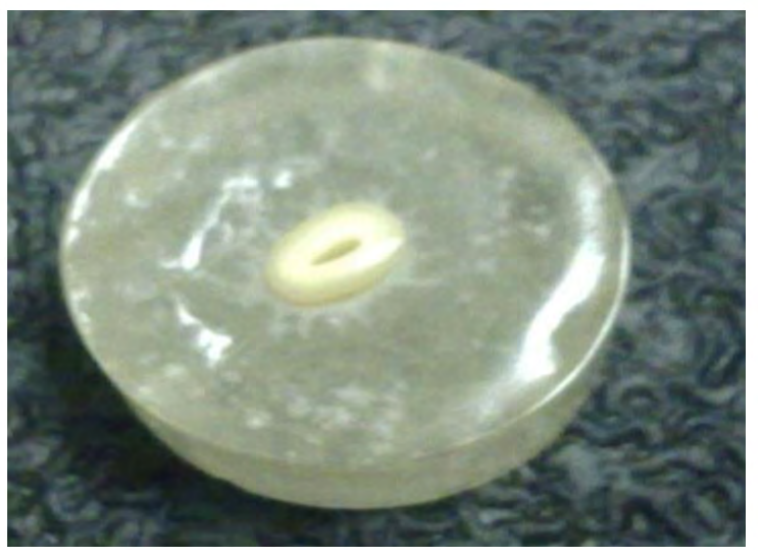

Figure 1: The acrylic resin block.

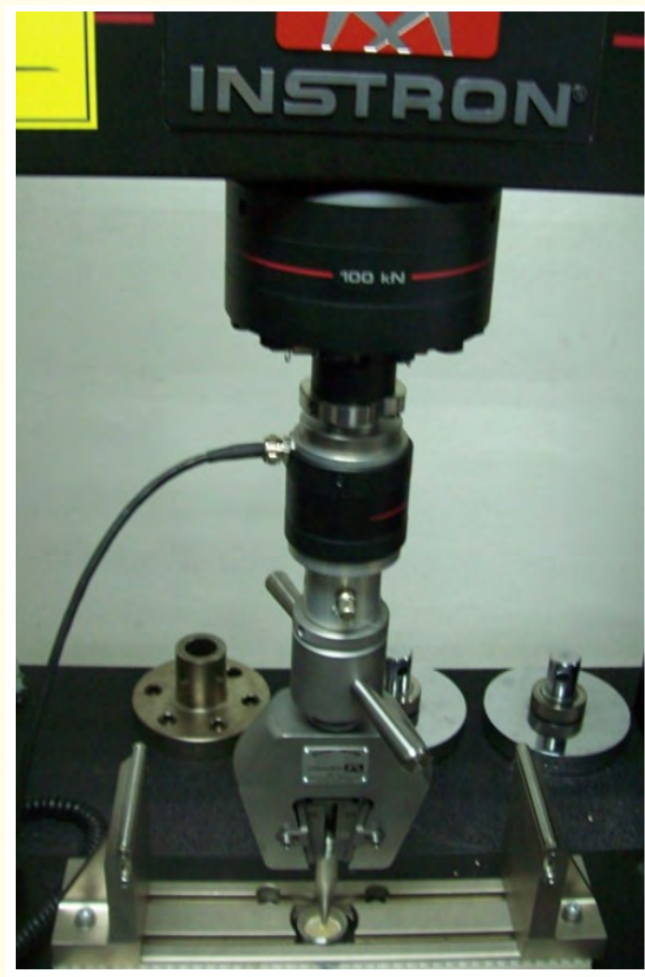

Figure 2: Instron universal testing machine.

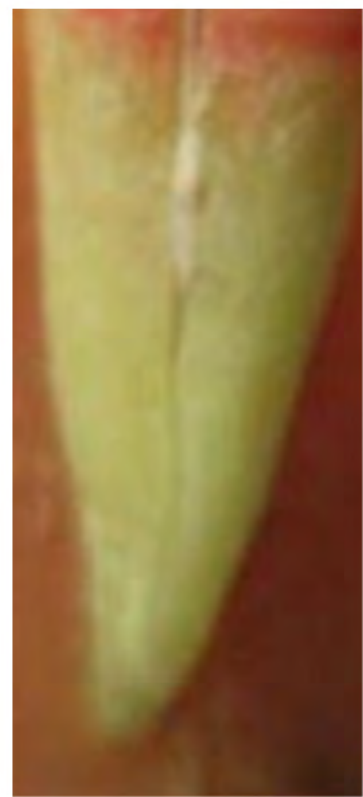

Figure 3: Fracture of the root.

\section{Results}

SPSS V.25 (IBM, New York, USA) was used to perform the analysis. Descriptive analysis was shown that the highest mean of fracture resistance with values (in N) was observed in Group 6 (positive control) 1279.3 (205.4), followed by Group 1 (Totalfill BC) 958.1 (79.2), Group 2 (AH plus) 888 (76.7), Group 3 (Apexit Plus) 736.1(66.5), Group 4 (Tubliseal) 719.8 (56.8). While Group 5 (negative control) shows the lowest mean value 493.5 (103.5).

The ANOVA test (Table 2) showed a significant difference among groups by setting a level of significance at $\mathrm{P} \leq 0.001$. Post hoc Tukey's test was done for multiple comparisons showing difference between each pair of the groups (Table 3). It was seen that Group (1) showed statistically nonsignificant difference when compared with Group (2), however Group (1) has statistically significant difference with the other groups. There was no statistically significant difference between Group (3) and Group (4). The negative control group showed a significant difference with all other groups $(\mathrm{p} \leq 0.001)$. At the same time there is statistically significant difference between positive control group and the other groups $(\mathrm{p} \leq 0.001)$. 


\section{Statistical analysis results}

Descriptive analysis (means and Standard deviations) and normality results of all groups are shown in table 1 and figure 4.

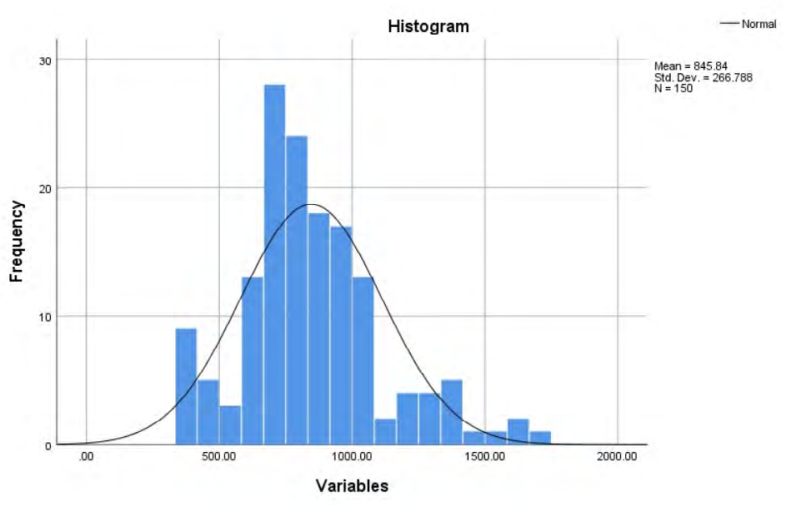

Figure 4: Normal distribution of all groups.

\begin{tabular}{|l|c|}
\hline \multicolumn{1}{|c|}{ Groups } & Mean/SD \\
\hline All groups & $845.84 \pm 266.78$ \\
\hline TotalFill BC Sealer & $958.16 \pm 79.20$ \\
\hline AH+Sealer & $888 \pm .76 .78$ \\
\hline Apexit Sealer & $736.16 \pm 66.56$ \\
\hline Tubliseal Sealer & $719.84 \pm 56.85$ \\
\hline positive group & $1279.32 \pm 205.47$ \\
\hline negative group & $493.52 \pm 103.58$ \\
\hline
\end{tabular}

Table 1: Mean/SD of all groups.

One way ANOVA was used to determine the difference between groups and the result was; There is significant difference between groups $\mathrm{P} \leq 0.001$ (Table 2 ).

\begin{tabular}{|l|c|c|c|c|c|}
\hline \multicolumn{7}{|c|}{ ANOVA } \\
\hline & Sum of Squares & df & Mean Square & F & Sig. \\
\hline $\begin{array}{l}\text { Between } \\
\text { Groups }\end{array}$ & 8858415.440 & 5 & 1771683.088 & 146.053 & .000 \\
\hline $\begin{array}{l}\text { Within } \\
\text { Groups }\end{array}$ & 1746774.720 & 144 & 12130.380 & & \\
\hline Total & 10605190.160 & 149 & & & \\
\hline
\end{tabular}

Table 2: The statistical difference between groups (one way ANOVA).

\begin{tabular}{|c|c|c|c|}
\hline Groups & Groups & P Value & Significance \\
\hline $\begin{array}{l}\text { Totalfill BC } \\
\text { Sealer }\end{array}$ & $\mathrm{AH}+$ Sealar & .412 & $\begin{array}{c}\text { Not signifi- } \\
\text { cant }\end{array}$ \\
\hline $\begin{array}{l}\text { Totalfill BC } \\
\text { Sealer }\end{array}$ & $\begin{array}{l}\text { Apexit+ } \\
\text { Sealer }\end{array}$ & $P \leq 0.001$ & Significant \\
\hline $\begin{array}{l}\text { Totalfill BC } \\
\text { Sealer }\end{array}$ & Tubiseal Seale & $P \leq 0.001$ & Significant \\
\hline $\begin{array}{l}\text { Totalfill BC } \\
\text { Sealer }\end{array}$ & Positive & $P \leq 0.001$ & Significant \\
\hline $\begin{array}{l}\text { Totalfill BC } \\
\text { Sealer }\end{array}$ & Negative & $P \leq 0.001$ & Significant \\
\hline $\mathrm{AH}+$ Sealer & $\begin{array}{l}\text { Apexit + } \\
\text { Sealer }\end{array}$ & $P \leq 0.001$ & Significant \\
\hline $\mathrm{AH}+$ Sealer & $\begin{array}{c}\text { Tubiseal } \\
\text { Sealer }\end{array}$ & $P \leq 0.001$ & Significant \\
\hline $\mathrm{AH}+$ Sealer & Positive & $P \leq 0.001$ & Significant \\
\hline $\mathrm{AH}+$ Sealer & Negative & $P \leq 0.001$ & Significant \\
\hline Apexit + Sealer & $\begin{array}{c}\text { Tubiseal } \\
\text { Sealer }\end{array}$ & .998 & $\begin{array}{c}\text { Not } \\
\text { significant }\end{array}$ \\
\hline Apexit+ Sealer & Positive & $P \leq 0.001$ & Significant \\
\hline Apexit+ Sealer & Negative & $P \leq 0.001$ & Significant \\
\hline Tubiseal Sealer & Positive & $P \leq 0.001$ & Significant \\
\hline Tubiseal Sealer & Negative & $P \leq 0.001$ & Significant \\
\hline Positive & Negative & $P \leq 0.001$ & Significant \\
\hline
\end{tabular}

Table 3: Multiple Comparisons, Post Hoc, showing difference between each pair of the groups.

\section{Discussion}

The prime objective of root canal sealer are to lubricate, obliterate discrepancies such as lateral canals and grooves that cannot be filled with Gutta-percha and facilitate adhesiveness to enhance the seal and stability of the root canal filling [13-16].

A golden requisite for a sealer to be ideal is to reinforce the remaining root structure by having a high fracture resistance and adhesiveness in conjunction with the obturating material. Therefore, in this study the universal testing machine was used to measure the fracture resistance of the several root canal sealers. The result of this study showed that root obturated with group 1 (Totalfill BC) sealer had higher resistance $(\mathrm{P}<0.001)$ to fracture when compared to groups 3 (Apexit Plus) sealer and group 4 (Tubliseal) sealer. Although group 1 (Totalfill $\mathrm{BC}$ ) sealer has higher fracture resistance than group 2 epoxy resin (AH plus) sealer but there were statisti- 
cally non-significant difference which agreed with Yendrembam., et al. study [17].

This result in agreed with the previous study of Nagas., et al. [18], where they found that MTA-Fillapex, iRoot SP had the highest adhesion and can't be detached from the root dentin when compared with AH Plus. They concluded that wet canal increase the bond strength and adhesion of bioceremic sealer to radicular dentin.

Bioceramic-based sealers created a strong bonds between the dentin and core filling materials [19] which is comparable to that of AH Plus and better than either Sealapex or EndoREZ sealers [20]. A study found that the presence of smear layer has no significant difference on dislocation resistance of Bioceramic sealer and $\mathrm{AH}$ Plus sealer [21].

During setting, bioceramic sealer forms apatite as a result of releasing calcium and hydroxyl ions. This apatite is deposited along collagen fibrils and increases the formation of inorganic nucleation. This creates formation of interfacial layer with tag-like features in dentine. The chemical bond thus formed may strengthen the tooth obturated with bioceramic sealer.

It was suggested that the particle size could improve the bonding by increasing the micromechanical retention of the sealer [22].

In the current study epoxy resin (AH Plus) sealer indicated higher with significant difference in fracture values than those $\mathrm{Ca}(\mathrm{OH})_{2}$ Apexit plus group sealer and ZOE Tubliseal group.

$\mathrm{AH}$ Plus has the ability to form covalent bond between the resin and amino groups in the collagen. AH Plus has a creeping and viscosity properties, as a result it can penetrate into dentinal tubule, increase the flowability and the mechanical interlocking between the sealer and root dentin $[23,24]$.

In this study ZOE (Tubliseal) group showed lower fracture resistance values as compared to $\mathrm{Ca}(\mathrm{OH})_{2}$ (Apexit plus) group with statistically insignificant. The difference because $\mathrm{Ca}(\mathrm{OH})_{2}$ has less micro- leakage value than ZOE [25]. In addition, initial release of hydroxyl ions from $\mathrm{Ca}(\mathrm{OH})_{2}$ might induce a biological formation of hard tissue apically, which minimize long-term dissolution [26].

In the current study ZOE (tubiseal) group demonstrated the lowest fracture resistance among the four sealers studied. These results are in agreement with the studies of McComb and Smith, who concluded that ZOE sealer showed no adhesive properties [27].

In addition, it was observed that sound roots has the highest statistically significant difference to fracture resistance among the groups, followed by TotalFill BC Sealer. This is because Totalfill BC sealer has a special Totalfill BC obturating points which are coated and impregnated with bioceramic nanoparticles. The combination use of the sealer and TotalFill BC Points obtains homogenous adhesion and bond to dentine, thereby this might increase the fracture resistance propriety. This findings agrees with Mohammed and $\mathrm{Al}$ Zaka [28] and disagreed with Phukan., et al. [29].

\section{Conclusion}

- Roots obturated with TotalFill BC Sealer and TotalFill points showed the highest loading force value to fracture amongst the sealer groups followed by AH plus.

- It can be concluded that TotalFill BC sealer may strengthen the root canal treated tooth.

- This high fracture resistance of TotalFill BC sealer might be due to the special Totalfill point, which made a good adhesion

- Further studies are required to clarify and to compare the fracture resistance outcomes associated with the use of other bioceramic sealers.

\section{Acknowledgments}

The author has declared that no financial support was received from any organization for the submitted work.

\section{Financial Support and Sponsorship}

Nil.

\section{Conflicts of Interest}

There are no conflicts of interest.

\section{Bibliography}

1. Gutmann J L. "The dentin-root complex: anatomic and biologic considerations in restoring endodontically treated teeth". Journal of Prosthetic Dentistry 67.4 (1992): 458-467.

2. Tang W., et al. "Identifying and reducing risks for potential fractures in endodontically treated teeth". Journal of Endodontics 36.4 (2010): 609-617. 
3. Bhat SS., et al. "Evaluation of resistance of teeth subjected to fracture after endodontic treatment using different root canal sealers: An in vitro study". Journal of Indian Society of Pedodontics and Preventive Dentistry 30 (2012): 305-309.

4. Kazemi BR., et al. "Dimensional changes of endodontic sealers”. Oral Surgery, Oral Medicine, Oral Pathology 76 (1993): 766.

5. Peters DD. "Two-year in vitro solubility evaluation of four gutta-percha sealer obturation techniques". Journal of Endodontics 12 (1986): 139.

6. Khedmat S and Sedaghati M. "Comparison of the tensile strength of four root canal sealers". Journal of Dentistry (Tehran) 3 (2006): 1-5.

7. McMichen FR., et al. "A comparative study of selected physical properties of five root-canal sealers". International Journal of Endodontics 36 (2003): 629-35.

8. Spanberg LS and Haapasalo M. "Rationale and efficacy of root canal medicaments and root filling materials with emphasis on treatment outcome". Endodontic Topics 2 (2002): 35-58.

9. Shantiaee Y., et al. "In vitro evaluation of the antibacterial activity of three root canal sealers". Iranian Endodontic Journal 5 (2010): 1-5.

10. Parirokh M and Torabinejad M. "Mineral trioxide aggregate: a comprehensive literature review. I. Chemical, physical, and antibacterial properties". Journal of Endodontics 36 (2010): 16.

11. Parirokh $\mathrm{M}$ and Torabinejad M. "Mineral trioxide aggregate: a comprehensive literature review. III. Clinical applications, drawbacks, and mechanism of action". Journal of Endodontics 36 (2010): 400.

12. Kebudi Benezra M., et al. "Interfacial characteristics and cytocompatibility of hydraulic sealer cements". Journal of Endodontics 44.6 (2018): 1007-1017.

13. Tomson RM., et al. "Contemporary obturation of the root canal system”. British Dental Journal 216.6 (2014): 315-322.

14. Duarte MAH., et al. "Tricalcium silicate-based cements: Properties and modifications". Brazilian Oral Research 32 (2018): e70.
15. Evans JT and Simon JH. "Evaluation of the apical seal produced by injected thermoplasticized gutta-percha in the absence of smear layer and root canal sealer". Journal of Endodontics 12.2 (1986): 101-107.

16. Hata I., et al. "Sealing ability of Thermafil with or without sealer”. Journal of Endodontics 18.7 (1992): 322-336.

17. Yendrembam B., et al. "Relative assessment of fracture resistance of endodontically treated teeth with epoxy resinbased sealers, AH plus, MTA Fillapex, and bioceramic sealer: an in vitro study". Indian Journal of Dental Sciences 11.1 (2019): 4650.

18. Nagas E., et al. "Dentin moisture conditions affect the adhesion of root canal sealers". Journal of Endodontics 38.2 (2012): 240-244.

19. Koch K and Brave D. "A new day has dawned: the increased use of bioceramics in endodontics". Dental Town 10 (2009): 39-43.

20. Ersahan S and Aydin C. "Dislocation resistance of iRoot SP, a calcium silicate-based sealer, from radicular dentine". Journal of Endodontics 36.12 (2010): 2000-2002.

21. Shokouhinejad N., et al. "Push-out bond strength of gutta-percha with a new bioceramic sealer in the presence or absence of smear layer". Australian Endodontic Journal 39.3 (2013): 102-106

22. Torabinejad M., et al. "Mineral trioxide aggregate and other bioactive endodontic cements: an updated overview - part II: other clinical applications and complications". International Endodontic Journal 51.3 (2018): 284-317.

23. Chadha R., et al. "An in vitro comparative evaluation of fracture resistance of endodontically treated teeth obturated with different materials". Contemporary Clinical Dentistry 1.2 (2010): 70-72.

24. Nunes VH., et al. "Adhesion of Epiphany and AH plus sealers to human root dentin treated with different solutions". Brazilian Dental Journal 19.1 (2008): 46-50.

25. Siqueira JF Jr and Rôças IN. "Bacterial pathogenesis and mediators in apical periodontitis". Brazilian Dental Journal 18 (2007): 267-280. 
26. Siqueira JF., et al. "Evaluation of sealing ability, pH and flow rate of three calcium hydroxide-based sealers". Endodontics and Dental Traumatology 11 (1995): 225-228.

27. McComb D and Smith DC. "Comparison of physical properties of polycarboxylate-based and conventional root canal sealers". Journal of Endodontics 2 (1976): 228-235.

28. Mohammed T Y., et al. "Fracture Resistance of Endodontically Treated Teeth Obturated with Different Root Canal Sealers (A Comparative Study)". Journal of Contemporary Dental Practice 21.5 (2020): 490-493.

29. Phukan AH., et al. "The effect of different root canal sealers on the fracture resistance of endodontically treated teeth-in vitro study". Journal of Dental Research (Isfahan) 14.6 (2017): 382-388.

\section{Assets from publication with us}

- Prompt Acknowledgement after receiving the article

- Thorough Double blinded peer review

- Rapid Publication

- Issue of Publication Certificate

- High visibility of your Published work

Website: www.actascientific.com/

Submit Article: www.actascientific.com/submission.php

Email us: editor@actascientific.com

Contact us: +919182824667 